\title{
Association of air pollution and use of glyceryl trinitrate against angina pectoris: a population-based case-crossover study
}

\author{
Ragnhildur Gudrun Finnbjornsdottir ${ }^{1}$, Helga Zoëga', Orn Olafsson ${ }^{1}$, Throstur Thorsteinsson ${ }^{2,3}$ \\ and Vilhjalmur Rafnsson ${ }^{4^{*}}$
}

\begin{abstract}
Background: Ambient air pollution has been associated with increased cardiovascular morbidity and mortality. In Reykjavik, Iceland, air pollutant concentrations exceed official health limits several times every year. The aim was to study the association of concentrations of $\mathrm{NO}_{2}, \mathrm{O}_{3}, \mathrm{PM}_{10}$, and $\mathrm{H}_{2} \mathrm{~S}$ in the Reykjavik capital area with the dispensing of anti-angina pectoris medication, glyceryl trinitrate to the inhabitants.

Methods: Data on daily dispensing of glyceryl trinitrate, were retrieved from the Icelandic Medicines Registry. Data on hourly concentrations of $\mathrm{NO}_{2}, \mathrm{O}_{3}, \mathrm{PM}_{10}$, and $\mathrm{H}_{2} \mathrm{~S}$ were obtained from the Environment Agency of Iceland. A case-crossover design was used, based on the dispensing of glyceryl trinitrate to 5,246 individuals ( $\geq 18$ years) between 2005 and 2009.

Results: For every $10 \mu \mathrm{g} / \mathrm{m}^{3}$ increase of $\mathrm{NO}_{2}$ and $\mathrm{O}_{3}$ 3-day mean concentrations, the odds ratio (OR) for daily dispensing of glyceryl trinitrates was 1.136 (95\% confidence intervals (Cl) 1.069-1.207) and 1.094 (95\% Cl 1.029-1.163) at lag 0, and OR was $1.096(95 \% \mathrm{Cl} 1.029-1.168)$ and 1.094 (95\% Cl 1.028-1.166) at lag 1, respectively.

Conclusions: These findings suggest that $\mathrm{NO}_{2}$ and $\mathrm{O}_{3}$ ambient air concentrations may adversely affect cardiovascular health, as measured by the dispensing of glyceryl trinitrates for angina pectoris. Further, the findings suggest that data on the dispensing of medication may be a valuable health indicator when studying the effect of air pollution on cardiovascular morbidity.
\end{abstract}

Keywords: Air pollution, Angina pectoris, Coronary disease, Case-crossover, Drug utilization, Nitrogen dioxide, Ozone, Pharmacoepidemiology

\section{Background}

In previous studies an increased risk of cardiovascular morbidity and mortality has been found in association with exposure to air pollution [1-3]. In these studies different outcome measures were used such as hospital admission [4], emergency department visits [5], or deaths $[6,7]$ due to cardiovascular diseases. On the other hand, some studies do not show an association between the risk of cardiovascular morbidity and mortality and air pollution $[8,9]$.

Zeghnoun and coworkers [10] introduced the dispensing of respiratory drugs as a novel indicator to measure

\footnotetext{
* Correspondence: vilraf@hi.is

${ }^{4}$ Department of Preventive Medicine, University of Iceland, Reykjavík, Iceland Full list of author information is available at the end of the article
}

respiratory morbidity in association with air pollution. They implied that drug dispensing generally reflects less severe morbidity states than those resulting in emergency department visits, hospitalizations or death, and could therefore serve as a sensitive marker to measure the effects of air pollution in small populations where mortality rates are low. Since then, only a few studies have investigated the association of air pollution and the dispensing of anti-asthma drugs as an indicator of respiratory symptoms or asthma attacks [11-14].

To our knowledge, the dispensing of medication for cardiovascular diseases has not previously been used to estimate the possible effect of ambient air pollution on cardiovascular health. In the following study, the aims were to evaluate the association of changes in ambient

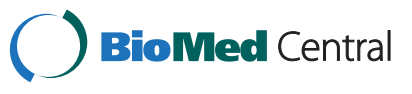


air concentrations of $\mathrm{NO}_{2}, \mathrm{O}_{3}, \mathrm{PM}_{10}$, and $\mathrm{H}_{2} \mathrm{~S}$ with dispensing of the sublingual medication glyceryl trinitrate used against attacks of angina pectoris.

\section{Methods}

The study base consisted of inhabitants 18 years or older in the Reykjavik capital area (communities: Reykjavik, Seltjarnarnes, Kopavogur, Hafnarfjordur, Gardabaer, and Mosfellsbaer) identified by postal codes (Figure 1). According to Statistics Iceland the annual mean population was 142,789 individuals ( $\geq 18$ years) [15]. The study period was January 1, 2005 to December 31, 2009.

\section{Exposure and covariate assessment}

The Environment Agency of Iceland provided the exposure data. The agency continuously measures air pollution levels of various pollutants at a busy intersection of two main roads in Reykjavik (Grensasvegur-Miklabraut) where on average around 60,000 cars cross daily (Figure 1) [16]. In this study, 1-hour measurements were obtained for $\mathrm{NO}_{2}, \mathrm{O}_{3}, \mathrm{PM}_{10}$, and $\mathrm{H}_{2} \mathrm{~S}$ concentrations. Gaps in exposure measurements were due to occasionally inactive measuring equipment. $\mathrm{PM}_{10}$ was measured with an Andersen EMS IR Thermo (model FH62 I - R, Thermo Scientific, United States) and $\mathrm{NO}_{2}, \mathrm{H}_{2} \mathrm{~S}$, and $\mathrm{O}_{3}$ with a Horiba (models APNA 360E, APSA 360ACE, and APOA 360E, Horiba, United States). These devices are calibrated every six to twelve months.
The entire dataset contained 1,826 days ( 5 years). The 24-hour mean concentration values (from the time 00:00 to 00:00 the following day) were calculated for each pollutant, using the 1-hour values where at least $75 \%$ of the data existed. The number of days in which the $75 \%$ criterion was fulfilled varied by pollutant; missing 24-hour values were $143(8 \%)$ for $\mathrm{NO}_{2}, 83(4 \%)$ for $\mathrm{O}_{3}$, and 36 (2\%) for $\mathrm{PM}_{10} \cdot \mathrm{H}_{2} \mathrm{~S}$ measurements started on February 22, 2006 and therefore do not provide complete data. $\mathrm{H}_{2} \mathrm{~S}$ measurements thus contribute 1,409 days to the dataset, for which 219 days (15\%) were missing. The $\mathrm{NO}_{2}, \mathrm{O}_{3}$, and $\mathrm{PM}_{10}$ are traffic related, however deserts dust and volcanic ashes contribute to the concentration of $\mathrm{PM}_{10}$ in the Reykjavik area depending on wind direction. The source of $\mathrm{H}_{2} \mathrm{~S}$ is two geothermal power plants 26 and $33 \mathrm{~km}$ east of the city. For meteorological data, 24-hour mean values were retrieved from the same measurement location as for the pollutants. Missing days were $13(<1 \%)$ for temperature and relative humidity $(\mathrm{RH})$. Missing values were not associated with any particular day in the week. The 3-day means were calculated for each pollutant and meteorological data based on 24-hour values, giving the running averages of the day when dispensing occurred (index day), one day before and two days before the index day, so the 3-day means included the day of dispensing.

Monthly numbers of influenza cases were obtained from the Directorate of Health and were recalculated

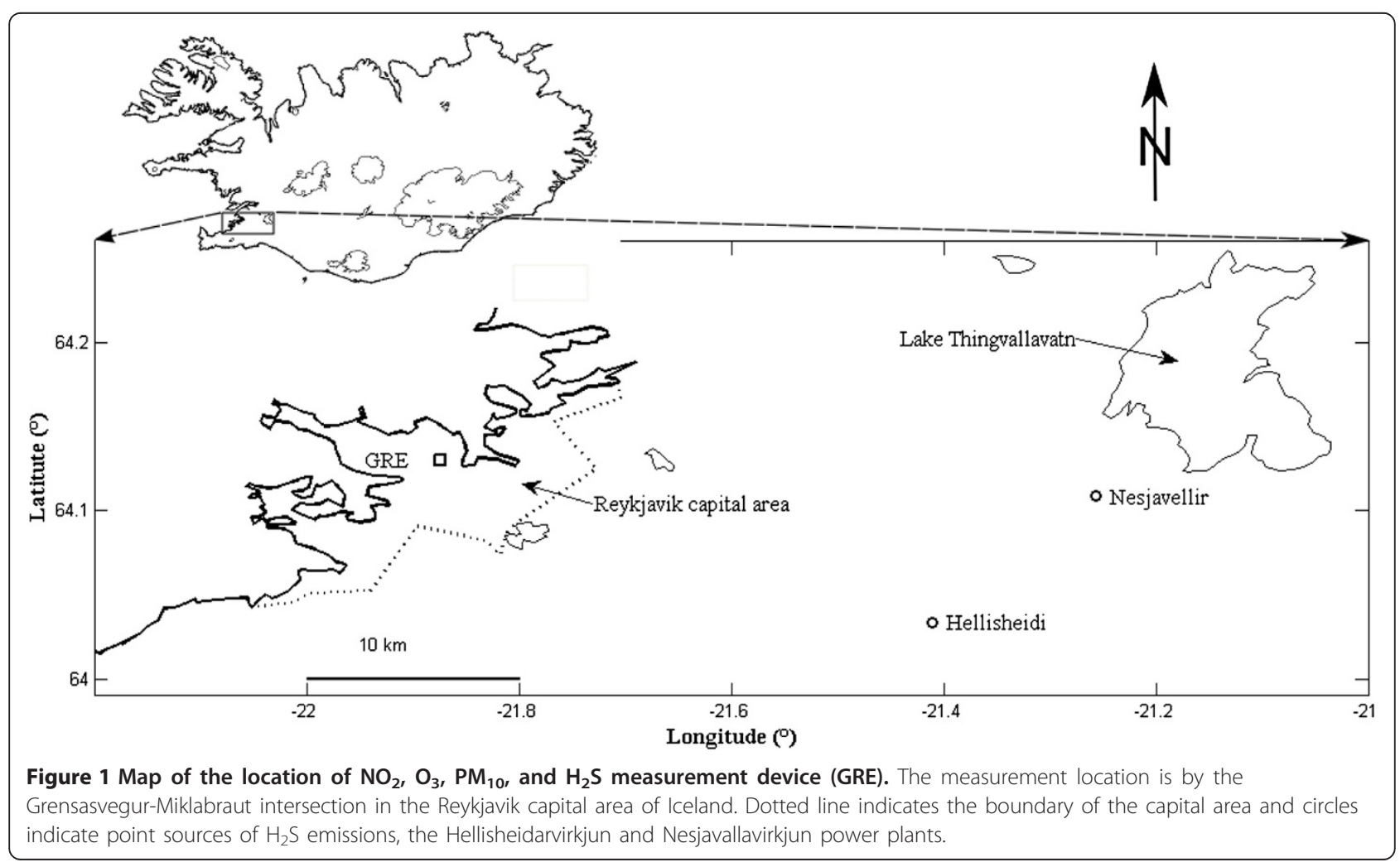


into binary variables with a cut-off of 300 cases per month to define an influenza season.

\section{Case ascertainment}

The Icelandic Medicines Registry was the source of the outcome data and the registry contains information for each person to whom prescription medication was dispensed as an outpatient during the study period. The coverage of the database is virtually complete in the Reykjavik area for all filled prescriptions in outpatient settings [17]. For each occurrence of glyceryl trinitrate dispensing in the study we received information on medication name, number of defined daily doses (DDDs), Anatomic Therapeutic Chemical (ATC) code [18], dispensing date, encrypted personal identification number, sex, birth year, and residential postal code of the patient. The personal identification number allowed checking whether drug dispensing had occurred with seven days intervals, to avoid overlap with control days.

We retrieved information on all filled prescriptions defined as glyceryl trinitrates (ATC code: C01DA02), the target medication in this study. Glyceryl trinitrates are used against an abrupt onset of painful attacks of angina pectoris. An effective dose of glyceryl trinitrate administered sublingually acts within minutes, usually terminating pain quickly and completely, making it an ideal medication to study in association with air pollution fluctuations. No information on underlying medical conditions was available from the Icelandic
Medicines Registry. Other drugs used against angina pectoris were not taken into consideration in this study. These are long acting nitrates, beta blockers, and calcium channel blockers and when used against angina pectoris these medicines should be taken regularly. Beta blockers and calcium channel blockers are indicated for several other medical conditions than angina pectoris. The glyceryl trinitrate is the only medicine against angina pectoris used intermittently when the patient has an attack of chest pain. In the study all drug dispensing was according to prescription and it was not possible to differ between new prescription and renewal fills due to routine or exacerbation of symptoms. Some patients may have had prescription valid for up to four repeated fillings, and recognition of these prescriptions was not possible. A package of glyceryl trinitrate, which has been opened expires in eight weeks.

Three preconditions were needed to be defined as a case; 1 ) the individual was living in the Reykjavik capital area, 2) the individual was 18 years or older, and 3) glyceryl trinitrates were dispensed to the individual at least once over the study period. The total number of cases over the study period was 5,246.

\section{Design and data analysis}

Pearson's correlation was used to assess the intercorrelation between exposure factors and the meteorological covariates (Table 1).

Table 1 Air pollution statistics

\begin{tabular}{|c|c|c|c|c|c|c|c|c|c|c|}
\hline & \multirow[t]{2}{*}{ Days, $\mathbf{n}$} & \multirow[t]{2}{*}{ Mean (SD) } & \multirow[t]{2}{*}{ Min } & \multirow[t]{2}{*}{ Max } & \multicolumn{6}{|c|}{ Pearson's correlation coefficient } \\
\hline & & & & & $\mathrm{PM}_{10}$ & $\mathrm{NO}_{2}$ & $\mathrm{O}_{3}$ & $\mathrm{H}_{2} \mathrm{~S}$ & Rel. humidity, \% & Temperature, ${ }^{\circ} \mathrm{C}$ \\
\hline \multicolumn{11}{|l|}{ 24-hour mean } \\
\hline $\mathrm{PM}_{10}, \mu \mathrm{g} / \mathrm{m}^{3}$ & 1,790 & $22.6(20.8)$ & 3.2 & 261.6 & 1 & & & & & \\
\hline $\mathrm{NO}_{2}, \mu \mathrm{g} / \mathrm{m} 3$ & 1,683 & $20.8(13.5)$ & 0.7 & 100.6 & 0.13 & 1 & & & & \\
\hline $\mathrm{O}_{3}, \mu \mathrm{g} / \mathrm{m}^{3}$ & 1,744 & $40.7(13.8)$ & 1.2 & 144.5 & 0.13 & -0.62 & 1 & & & \\
\hline $\mathrm{H}_{2} \mathrm{~S}, \mu \mathrm{g} / \mathrm{m}^{3}$ & 1,190 & $3.8(6.7)$ & 0.0 & 92.5 & 0.02 & 0.34 & -0.28 & 1 & & \\
\hline Rel. humidity, \% & 1,813 & $77.8(10.9)$ & 39.3 & $102.5^{\mathrm{a}}$ & -0.33 & 0.04 & -0.07 & 0.03 & 1 & \\
\hline Temperature, ${ }^{\circ} \mathrm{C}$ & 1,813 & $5.9(5.2)$ & -10.3 & 22.2 & -0.28 & -0.43 & -0.04 & -0.28 & 0.15 & 1 \\
\hline 3-day mean & & & & & $\mathrm{PM}_{10}$ & $\mathrm{NO}_{2}$ & $\mathrm{O}_{3}$ & $\mathrm{H}_{2} \mathrm{~S}$ & Rel. humidity, \% & Temperature, ${ }^{\circ} \mathrm{C}$ \\
\hline $\mathrm{PM}_{10}, \mu \mathrm{g} / \mathrm{m}^{3}$ & 1,811 & $20.5(15.3)$ & 4.6 & 125.7 & 1 & & & & & \\
\hline $\mathrm{NO}_{2}, \mu \mathrm{g} / \mathrm{m}^{3}$ & 1,707 & 20.7 (10.9) & 0.7 & 100.6 & 0.11 & 1 & & & & \\
\hline $\mathrm{O}_{3}, \mu \mathrm{g} / \mathrm{m}^{3}$ & 1,765 & $40.8(11.5)$ & 5.8 & 108.9 & 0.22 & -0.52 & 1 & & & \\
\hline $\mathrm{H}_{2} \mathrm{~S}, \mu \mathrm{g} / \mathrm{m}^{3}$ & 1,282 & $3.8(5.1)$ & 0.1 & 69.5 & -0.01 & 0.41 & -0.29 & 1 & & \\
\hline Rel. humidity, \% & 1,824 & $77.8(9.1)$ & 43.0 & $101.2^{\mathrm{a}}$ & -0.34 & 0.03 & -0.07 & 0.05 & 1 & \\
\hline Temperature, ${ }^{\circ} \mathrm{C}$ & 1,824 & $5.9(5.0)$ & -7.3 & 18.2 & -0.43 & -0.48 & -0.12 & -0.34 & 0.14 & 1 \\
\hline
\end{tabular}

Abbreviations: $\mathrm{H}_{2} \mathrm{~S}$ : hydrogen sulfide; Max: maximum value over specific time period; Mean: mean value over specified time period; Min: minimum value over specific time period; $\mathrm{NO}_{2}$ : nitrogen dioxide; $\mathrm{O}_{3}$ : ozone; $\mathrm{PM}_{10}$ : particulate matter with an aerodynamic diameter of $\leq 10 \mu$ m; Rel. humidity: relative humidity; $\mathrm{SD}$ : standard deviation.

${ }^{a}$ The maximum value of relative humidity is $100 \%$. There is a $2.5 \%$ error margin in the measuring equipment.

Description of air pollution in Reykjavik, Iceland, over the study period of January $1^{\text {st }} 2005$ to December $31^{\text {st }} 2009$. 24-hour mean values and 3-day mean values are shown as well as Pearson's correlation coefficient between pollutant factors. 
A case-crossover design was used, as it is suitable for studying the association of transient exposure, such as air pollution, and an acute onset event, such as the dispensing of anti-angina pectoris medication, glyceryl trinitrate [19]. The symmetric bidirectional design with selection of two controls, seven days before and after the index day (day of dispensing glyceryl trinitrate) was used [20]. The case-crossover design compares each person's exposure experience in a time period just prior to the case-defining event with that same person's exposure experience seven days before and seven days after the event. This matches controls for measured or unmeasured personal confounding characteristics that do not vary over the relatively short time, such as gender, age, and genetic factors [20].

We conducted several calculations including single pollutants $\mathrm{NO}_{2}, \mathrm{O}_{3}, \mathrm{PM}_{10}, \mathrm{H}_{2} \mathrm{~S}$, temperature, humidity, and influenza seasons to each single pollutant model. Two separate multi pollutant models were used, one introducing three pollutants, $\mathrm{NO}_{2}, \mathrm{O}_{3}$, and $\mathrm{PM}_{10}$, based on 24-hour means of the pollutants, and another introducing four pollutants, $\mathrm{NO}_{2}, \mathrm{O}_{3}, \mathrm{PM}_{10}$, and $\mathrm{H}_{2} \mathrm{~S}$ both adjusted for temperature and humidity on the same day. Finally, all models were also run with pollutant exposure averaged over three consecutive days (3-day means), also adjusted for temperature and humidity. These models were also run with and without adjustment for the influenza periods.

A lag time up to three days was introduced in the analyses according to the following definitions: lag 0: air pollution exposure on the dispensing day, lag 1-3: air pollution exposure one day before (lag 1) and up to three days before (lag 3 ) the dispensing day. We obtained estimates of odds ratios (OR) for the association of each pollutant, using conditional logistic regression. Sets were excluded if there were two or more missing values in the matched case control set (a complete set contains three exposure values). We reported effects estimates as the change in dispensing of glyceryl trinitrate associated with $10 \mu \mathrm{g} / \mathrm{m}^{3}$ increase in 24-hour mean or 3-day mean pollutant levels.

A few conditional logistic regression calculations with different controls in the symmetric bidirectional casecrossover design were conducted. Firstly, both days of the bidirectional controls were used, i.e., the same day of the week one week before and one week after the index day; secondly, one control day was used, the same day of the week one week before the index day; thirdly, one control day was used, the same day of the week one week after the index day; and fourthly, one control day was randomly chosen from the same day of the week either a week before or a week after the index day. This fourth procedure is called semisymmetric bidirectional control selection [20]. If only one of these days was available, as a result of the case being at either the end of the exposure series, that day served as the sole control day. Overlap bias is avoided by the semisymmetric bidirectional design [20]. All these calculations gave nearly identical results and therefore the only results based on the symmetric bidirectional controls are shown in this presentation.

We used SPSS 16.0 (IBM software, United States) and STATA 11 (StataCorp, United States) for all analyses. The study protocol was approved by the National Bioethics Committee (ref. no. VSNb2010030008/03.7) and the Data Protection Authority (ref. no. 2010030105/ 5.2.3.3/SH/sh).

\section{Results}

\section{Descriptive statistics}

Excluding repeated dispensing occurrences to the same patient on the same day, glyceryl trinitrates were dispensed 8,604 times to a total of 5,246 individuals $(57.9 \%$ males, $40.1 \%$ females) over the study period. On average, dispensing of glyceryl trinitrate occurred 4-5 times each day to the patients in the study base, range 0 to 19 per day. The mean age of the patients was 74 years (median 76 years, interquartile range 67, 82 years). Around 98\% of individuals who used glyceryl trinitrates filled fewer than five prescriptions per year, and approximately $73 \%$ filled one prescription per year. The majority of dispensing occurrences took place on weekdays rather than on weekends or holidays.

$\mathrm{NO}_{2}$ and $\mathrm{O}_{3}$ followed a seasonal pattern with higher concentrations during winter, whereas such a pattern was not as clear for $\mathrm{PM}_{10}$ and $\mathrm{H}_{2} \mathrm{~S}$ (Figure 2). The 24-hour mean during winter months (November 1 to April 30) was $25 \mu \mathrm{g} / \mathrm{m}^{3}$ (standard deviation (SD) 15) and $43 \mu \mathrm{g} / \mathrm{m}^{3}$ (SD 15) for $\mathrm{NO}_{2}$ and $\mathrm{O}_{3}$, respectively. Over the summer months (May 1 to October 31) the 24-hour mean was $16 \mu \mathrm{g} / \mathrm{m}^{3}$ (SD 15) and $38 \mu \mathrm{g} / \mathrm{m}^{3}$ (SD 12) for the same pollutants. The inter-correlation was strongest between 24-hour mean concentration levels of $\mathrm{NO}_{2}$ and $\mathrm{O}_{3}$ where there was a negative correlation of -0.62 (Table 1), while the strongest positive correlation of 0.41 was between the 3-day means of $\mathrm{NO}_{2}$ and $\mathrm{H}_{2} \mathrm{~S}$. Temperature was negatively correlated with each pollutant and relative humidity correlated negatively with $\mathrm{PM}_{10}$ and $\mathrm{O}_{3}$ (Table 1 ).

\section{Air pollution and glyceryl trinitrate dispensing}

The matched OR and $95 \%$ CI for the dispensing of $g l y$ ceryl trinitrate associated with every $10 \mu \mathrm{g} / \mathrm{m}^{3}$ increase in $\mathrm{NO}_{2}, \mathrm{O}_{3}, \mathrm{PM}_{10}$, and $\mathrm{H}_{2} \mathrm{~S}$ 24-hour mean, as well as temperature, humidity, and influenza season in single pollutant model, applying lag 0 and 1 can be seen in Table 2 . A significant association was found between the dispensing of glyceryl trinitrate and the 24-hour mean concentrations of $\mathrm{NO}_{2}$ with lag 0 . Due to the low correlation between 

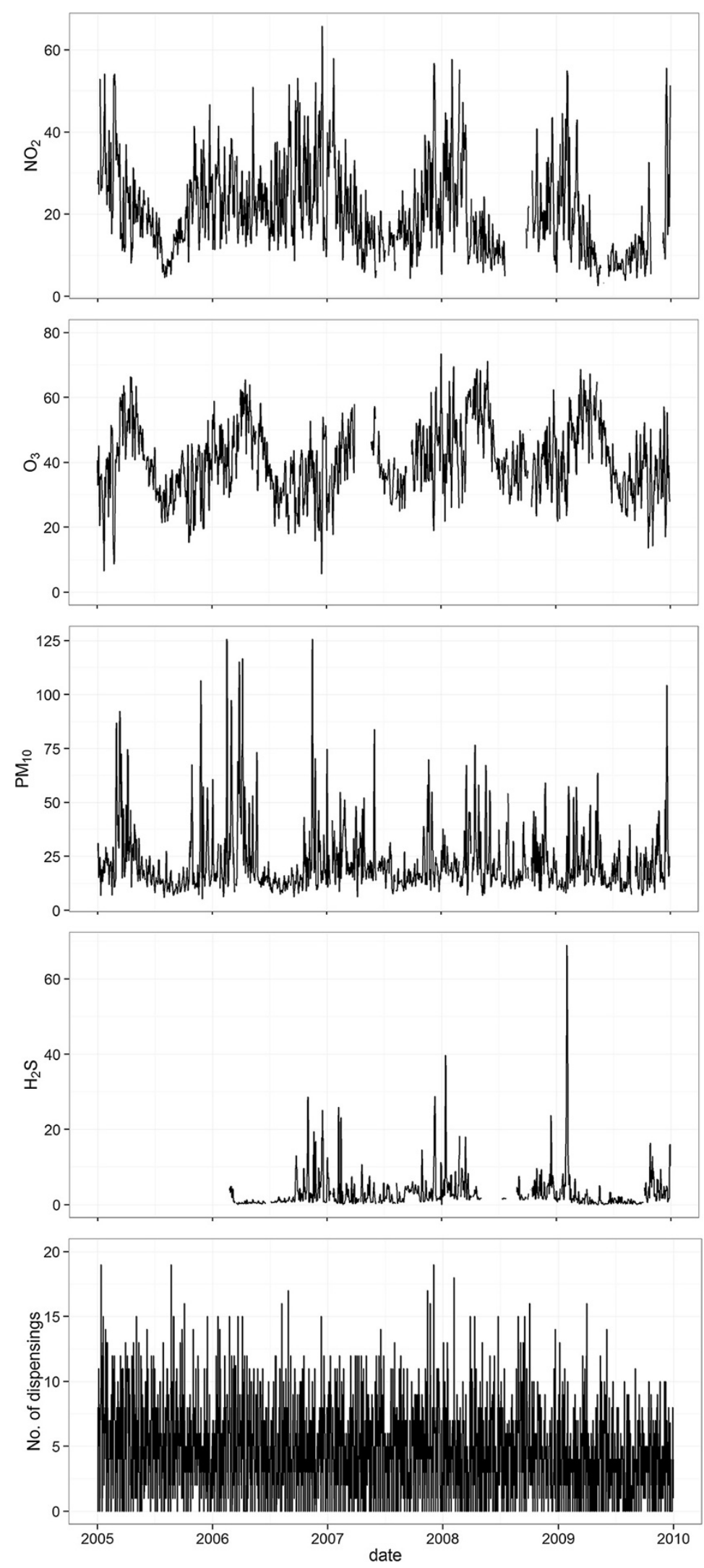

Figure 2 (See legend on next page.) 
pollutants (Table 1), and the complex exposure to many measured pollutants, a multipollutant model was also applied (Table 3). A significant positive association was found between the dispensing of glyceryl trinitrate and the 24-hour mean concentrations of $\mathrm{NO}_{2}$ and $\mathrm{O}_{3}$. At lag 0 and 1 a significant odds ratio (OR) of 1.059 (95\% CI: 1.012, 1.108) and 1.074 (95\% CI: 1.025, 1.126) for $\mathrm{NO}_{2}$ was evident. For $\mathrm{O}_{3}$, there was a significant $\mathrm{OR}$ of 1.087 (95\% CI: $1.035,1.141)$ at lag 1 . The multi-pollutant model was run with and without $\mathrm{H}_{2} \mathrm{~S}$ and when introducing $\mathrm{H}_{2} \mathrm{~S}$ in the model, the pattern of the association of the other exposure factors did not change. The $95 \% \mathrm{CI}$ of the ORs for 24-hour mean concentrations of $\mathrm{H}_{2} \mathrm{~S}$ and $\mathrm{PM}_{10}$ include unity at every time lag and are therefore not statistically significant (Table 3 ).

The 3-day mean concentration values yielded a stronger association than the 24-hour mean concentration values. At lag 0 the OR was 1.136 (95\% CI: 1.069, 1.207) and 1.094 (95\% CI: 1.029, 1.163) in daily occurrences of glyceryl trinitrate dispensing following an increase in the 3-day mean concentrations of $\mathrm{NO}_{2}$ and $\mathrm{O}_{3}$, respectively. At lag 1, the increase in occurrences of glyceryl trinitrate dispensing was 1.096 for $\mathrm{NO}_{2}(95 \%$ CI: $1.029,1.168)$ and 1.094 for $\mathrm{O}_{3}(95 \% \mathrm{CI}: 1.028,1.166)$. The OR at lag 2 and 3 was not statistically significant for either pollutant (Table 3 and Figure 3). $\mathrm{H}_{2} \mathrm{~S}$ showed a different pattern compared with $\mathrm{NO}_{2}$ and $\mathrm{O}_{3}$, where lag 0 and lag 1 showed a decrease (lag 0: 0.934; 95\% CI: 0.866, 1.008 and lag 1: 0.975; 95\% CI: 0.906, 1.048). At lag 2 and lag 3 there was an increase of 1.003 (95\% CI: 0.933, 1.079) and 1.027 (95\% CI: 0.951, 1.109), respectively. ORs for $\mathrm{H}_{2} \mathrm{~S}$ were not statistically significant at any time lag. $\mathrm{PM}_{10}$ also had a different pattern than the other pollutants where the OR was around 1 at every time lag and therefore not statistically significant at any time lag (Table 3 and Figure 3).
Introducing the influenza season to the models did not change the pattern of ORs for these exposures, as the ORs became only slightly elevated when the influenza season was included. The OR for influenza season was in no instance statistically significant as a confounder on a $5 \%$ level, except in the model when $\mathrm{H}_{2} \mathrm{~S}$ was not included and at lag 0 .

\section{Discussion}

In this study we found that exposure to urban air pollution was associated with the dispensing of glyceryl trinitrates (ATC code: C01DA02) among adults living in the Reykjavik area. The results show an increase of $13.6 \%$ and $9.6 \%$ in occurrences of glyceryl trinitrate dispensing for every $10 \mu \mathrm{g} / \mathrm{m}^{3}$ increase in the 3-day mean of $\mathrm{NO}_{2}$ at lag 0 and lag 1. Likewise, an increase of $9.4 \%$ and $9.4 \%$ in glyceryl trinitrate dispensing for every $10 \mu \mathrm{g} / \mathrm{m}^{3}$ increase the 3-day mean of $\mathrm{O}_{3}$ at lag 0 and lag 1 was evident.

Air pollution is believed to affect the biological pathway of the cardiovascular mechanism [21-23] but in what way is not yet clear. An experimental study on humans indicated that inhalation of fine particulate air pollution and ozone may cause acute arterial vasoconstriction that could lead to cardiovascular events [24]. A similar study showed that air pollution impairs endothelial function in young healthy males [25].

This study found an increase in dispensing of glyceryl trinitrate on the same day as increases $\mathrm{NO}_{2}$ and $\mathrm{O}_{3}$ occurred (lag 0). When an increase in $\mathrm{NO}_{2}$ and $\mathrm{O}_{3}$ occurred the day before (lag 1), there was also an increase in glyceryl trinitrate dispensing. This is evident for both 24-hour mean and 3-day mean concentrations. One of the major conditions for concluding on causality, that the exposure precedes the outcome, is fulfilled in the present study [26]. The 3-day mean of $\mathrm{NO}_{2}$ and $\mathrm{O}_{3}$ that

Table 2 Association of 24-hour air pollutant concentrations and glyceryl trinitrate dispensing in a single pollutant model

\begin{tabular}{|c|c|c|c|c|c|c|c|c|}
\hline \multirow[b]{2}{*}{ Lag } & \multicolumn{2}{|l|}{$\mathrm{NO}_{2}$} & \multicolumn{2}{|l|}{$\mathrm{O}_{3}$} & \multicolumn{2}{|l|}{$\mathrm{PM}_{10}$} & \multicolumn{2}{|l|}{$\mathrm{H}_{2} \mathrm{~S}$} \\
\hline & $\overline{\mathrm{OR}}$ & $95 \% \mathrm{Cl}$ & $\overline{\mathrm{OR}}$ & $95 \% \mathrm{Cl}$ & $\overline{\mathrm{OR}}$ & $95 \% \mathrm{Cl}$ & $\overline{\mathrm{OR}}$ & $95 \% \mathrm{Cl}$ \\
\hline 0 & 1.038 & $1.011,1.062$ & 0.988 & $0.965,1.012$ & 1.005 & $0.929,1.017$ & 0.997 & $0.991,1.004$ \\
\hline \multirow[t]{2}{*}{1} & 1.015 & $0.991,1.040$ & 1.017 & $0.993,1.041$ & 1.005 & $0.992,1.018$ & 0.937 & $0.874,1.000$ \\
\hline & \multicolumn{2}{|c|}{ Temperature } & \multicolumn{2}{|c|}{ Relative humidity } & \multicolumn{2}{|c|}{ Influenza seasons } & & \\
\hline Lag & OR & $95 \% \mathrm{Cl}$ & OR & $95 \% \mathrm{Cl}$ & OR & $95 \% \mathrm{Cl}$ & & \\
\hline 0 & 1.019 & $0.936,1.111$ & 1.020 & $0.994,1.046$ & 4.300 & $0.721,25.626$ & & \\
\hline 1 & 0.986 & $0.904,1.074$ & 1.001 & $0.976,1.027$ & 1.976 & $0.336,11.634$ & & \\
\hline
\end{tabular}

The matched odds ratios (OR) and $95 \%$ confidence intervals $(\mathrm{Cl})$ for the dispensation of glyceryl trinitrate in Reykjavik, Iceland, associated with every $10 \mu \mathrm{g} / \mathrm{m}^{3}$ increase in $\mathrm{NO}_{2}, \mathrm{O}_{3}, \mathrm{PM}_{10}, \mathrm{H}_{2} \mathrm{~S}$, temperature, and relative humidity 24-hour mean concentrations, and influenza seasons. 
Table 3 Association of air pollutants and glyceryl trinitrate dispensing in a multi-pollutant model

\begin{tabular}{|c|c|c|c|c|c|c|c|c|}
\hline \multirow[b]{2}{*}{ Lag } & \multicolumn{2}{|l|}{$\mathrm{NO}_{2}$} & \multicolumn{2}{|l|}{$\mathrm{O}_{3}$} & \multicolumn{2}{|l|}{$\mathrm{PM}_{10}$} & \multicolumn{2}{|l|}{$\mathrm{H}_{2} \mathrm{~S}$} \\
\hline & OR & $95 \% \mathrm{Cl}$ & OR & $95 \% \mathrm{Cl}$ & OR & $95 \% \mathrm{Cl}$ & OR & $95 \% \mathrm{Cl}$ \\
\hline \multicolumn{9}{|c|}{ 24-hour mean } \\
\hline \multicolumn{9}{|c|}{ Model not including $\mathrm{H}_{2} \mathrm{~S}$} \\
\hline 0 & 1.069 & $1.028,1.112$ & 1.036 & $0.995,1.078$ & 1.005 & $0.991,1.018$ & & \\
\hline 1 & 1.081 & $1.038,1.125$ & 1.088 & $1.045,1.133$ & 0.999 & $0.985,1.014$ & & \\
\hline 2 & 1.037 & $0.994,1.083$ & 1.036 & $0.995,1.080$ & 1.003 & $0.988,1.019$ & & \\
\hline 3 & 1.027 & $0.983,1.074$ & 1.020 & $0.978,1.064$ & 0.988 & $0.971,1.004$ & & \\
\hline \multicolumn{9}{|c|}{ Model including $\mathrm{H}_{2} \mathrm{~S}$} \\
\hline 0 & 1.059 & $1.012,1.108$ & 1.015 & $0.968,1.065$ & 1.002 & $0.985,1.020$ & 0.987 & $0.933,1.045$ \\
\hline 1 & 1.074 & $1.025,1.126$ & 1.087 & $1.035,1.141$ & 0.995 & $0.976,1.013$ & 0.958 & $0.907,1.013$ \\
\hline 2 & 1.054 & $1.003,1.108$ & 1.047 & $0.996,1.101$ & 1.001 & $0.982,1.020$ & 0.972 & $0.922,1.025$ \\
\hline 3 & 1.032 & $0.980,1.087$ & 1.028 & $0.976,1.083$ & 0.983 & $0.962,1.004$ & 1.030 & $0.979,1.083$ \\
\hline \multicolumn{9}{|c|}{3 day mean } \\
\hline \multicolumn{9}{|c|}{ Model not including $\mathrm{H}_{2} \mathrm{~S}$} \\
\hline 0 & 1.116 & $1.059,1.176$ & 1.090 & $1.036,1.146$ & 1.009 & $0.988,1.030$ & & \\
\hline 1 & 1.071 & $1.014,1.130$ & 1.072 & $1.019,1.129$ & 0.998 & $0.976,1.021$ & & \\
\hline 2 & 1.013 & $0.957,1.071$ & 1.018 & $0.965,1.073$ & 0.996 & $0.973,1.019$ & & \\
\hline 3 & 0.977 & $0.923,1.034$ & 0.990 & $0.938,1.046$ & 1.000 & $0.978,1.022$ & & \\
\hline \multicolumn{9}{|c|}{ Model including $\mathrm{H}_{2} \mathrm{~S}$} \\
\hline 0 & 1.136 & $1.069,1.207$ & 1.094 & $1.029,1.163$ & 0.998 & $0.972,1.024$ & 0.934 & $0.866,1.008$ \\
\hline 1 & 1.096 & $1.029,1.168$ & 1.094 & $1.028,1.166$ & 0.988 & $0.961,1.015$ & 0.975 & $0.906,1.048$ \\
\hline 2 & 1.045 & $0.978,1.117$ & 1.038 & $0.972,1.108$ & 0.983 & $0.956,1.012$ & 1.003 & $0.933,1.079$ \\
\hline 3 & 0.993 & $0.929,1.061$ & 0.997 & $0.933,1.065$ & 0.985 & $0.958,1.013$ & 1.027 & $0.951,1.109$ \\
\hline
\end{tabular}

Data have been calculated in a unique multivariate analysis separately for each lag, taking into account simultaneously each pollutant variables.

No. of observations for 24-hour mean not including $\mathrm{H}_{2} \mathrm{~S}$ : lag $0: 22,436$; lag 1: 22,327; lag 2: 22,288; and lag 3:22,367. No. of observations for 24-hour mean including $\mathrm{H}_{2} \mathrm{~S}$ : lag 0: 13,816; lag 1: 13,686; lag 2: 13,598; and lag 3: 13,650. No. of observations for 3-day mean not including $\mathrm{H}_{2} \mathrm{~S}$ : lag 0 : 21,913 ; lag 1: 21,755 ; lag 2: 21,617; and lag 3: 21,682. No. of observations for 3-day mean including $\mathrm{H}_{2} \mathrm{~S}$ : lag 0: 13,816; lag 1: 13,686; lag 2: 13,598; and lag 3: 13,650.

The matched odds ratios (OR) and $95 \%$ confidence intervals $(\mathrm{Cl})$ for the dispensation of glyceryl trinitrate in Reykjavik, Iceland, associated with every $10 \mu \mathrm{g} / \mathrm{m}^{3}$ increase in $\mathrm{NO}_{2}, \mathrm{O}_{3}, \mathrm{PM}_{10}$, and $\mathrm{H}_{2} \mathrm{~S}$ 24-hour mean and 3-day mean concentrations. Adjusted for each pollutant variable, temperature, and relative humidity.

is partly occurring before the index day gave higher ORs than the 24-hour mean concentrations, and thus a stronger association with the dispensing of glyceryl trinitrate.

Using the 3-day mean eliminates the possibility that the dispensing occurs before the exposure, whereas when using the 24-hour mean, the dispensing could theoretically occur during the exposure, as the 3-day mean yielded higher OR than the 24-hour mean. We also found a strong statistically significant increase in dispensing of glyceryl trinitrate at lag 1 for $\mathrm{NO}_{2}$ and $\mathrm{O}_{3}$, suggesting that patients use more glyceryl trinitrates when increases in the 3-day mean occur one day before the index day.

Concurrent with our results, Bhaskaran and coworkers [27] found that $10 \mu \mathrm{g} / \mathrm{m}^{3}$ increases in $\mathrm{NO}_{2}$ levels were associated with a $1.1 \%$ increased risk of myocardial infarction (MI) only 1-6 hours after the exposure occurred, a time frame that would have fallen within lag 0 in our study. However, we did not find an association between $\mathrm{PM}_{10}$ and glyceryl trinitrate dispensing, while Bhaskaran and coworkers demonstrated a $1.2 \%$ increase of MI with every $10 \mu \mathrm{g} / \mathrm{m}^{3}$ increase in $\mathrm{PM}_{10}$ [27]. Moreover, the Bhaskaran study is inconsistent with our results, in that they found no association between $\mathrm{O}_{3}$ and MI. Quite a few studies have demonstrated elevated relative risks, measured as MI [28,29], hospital admissions [30], and emergency department visits [31] due to cardiovascular diseases, on the same day and one day after increases in $\mathrm{NO}_{2}$ and $\mathrm{O}_{3}$ concentration occur (lag 0 and 1) [28,30]. Notably, von Klot and coworkers found a $1.32 \%$ increase in readmissions due to angina pectoris, the condition for which glyceryl trinitrates is prescribed, following an $8 \mu \mathrm{g} / \mathrm{m}^{3}$ increase in $\mathrm{NO}_{2}$ concentrations [30].

$\mathrm{PM}_{10}$ was not associated with glyceryl trinitrate dispensing at any lag in our study. Previous case-crossover studies have demonstrated an association of $\mathrm{PM}_{10}$ and $\mathrm{PM}_{2.5}$ with cardiovascular morbidity $[4,29,32]$. Some other studies have failed to find a statistically significant association of $\mathrm{PM}$ and cardiovascular morbidity $[8,9]$. Our findings concerning $\mathrm{PM}_{10}$ may be due to the relatively low $\mathrm{PM}_{10}$ levels in the Reykjavik area. Long-term 

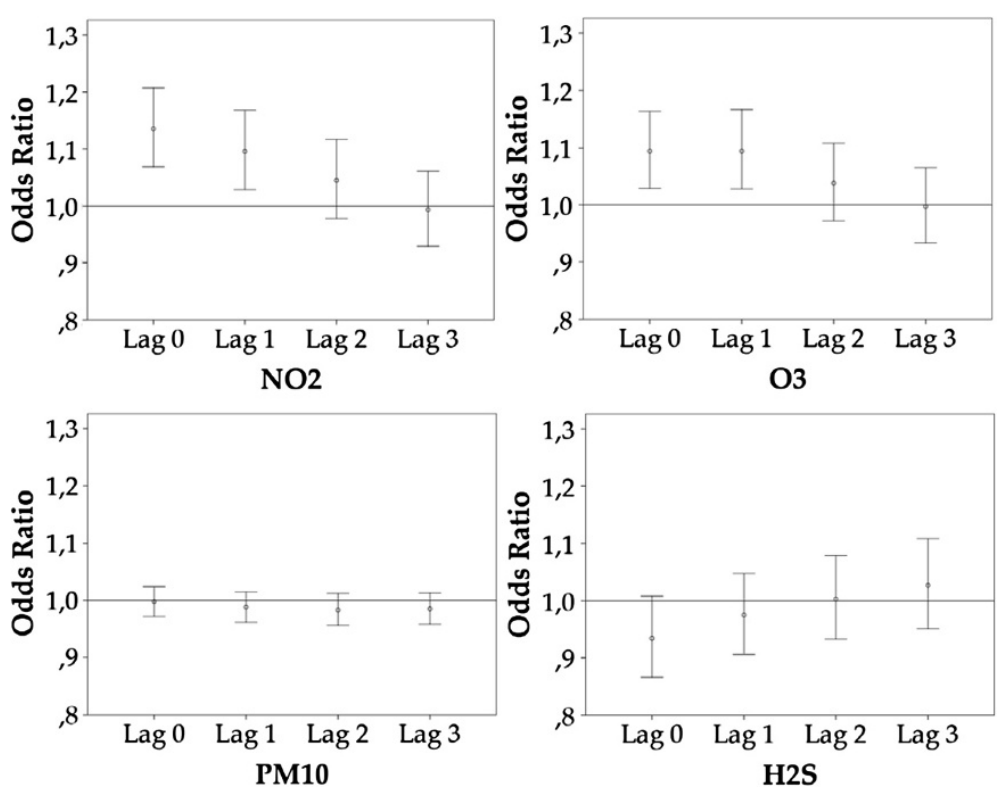

Figure 3 Association of $\mathrm{NO}_{2}, \mathrm{O}_{3}, \mathrm{PM}_{10}$, and $\mathrm{H}_{2} \mathrm{~S}$ exposure (3-day mean) and daily glyceryl trinitrate dispensing. Figure shows up to lag 0-3 days, adjusted for each pollutant variable, temperature, and relative humidity. Bars show $95 \%$ confidence intervals (Cl).

exposure to high concentrations of $\mathrm{PM}_{2.5}$ may adversely affect cardiovascular health. Still, the potential adverse effect of coarse particles $\left(\mathrm{PM}_{2.5-10}\right)$ should not be ignored. Unfortunately, we did not have access to $\mathrm{PM}_{2.5}$ measures and no information on the proportion of particles smaller than $2.5 \mu \mathrm{m}$ in aerodynamic diameter within the $\mathrm{PM}_{10}$ concentrations was available.

We did not find any statistically significant associations of increases in $\mathrm{H}_{2} \mathrm{~S}$ concentrations and glyceryl trinitrate dispensing at any time lag. However, introducing $\mathrm{H}_{2} \mathrm{~S}$ into the 3-day mean analysis yielded the highest OR for $\mathrm{NO}_{2}$ and $\mathrm{O}_{3}$ at lag 0 and lag 1 . So, $\mathrm{H}_{2} \mathrm{~S}$ did not seem to be an independent risk factor for glyceryl trinitrate dispensing. The possible effect of $\mathrm{H}_{2} \mathrm{~S}$ on cardiovascular morbidity has not been as intensively studied as $\mathrm{NO}_{2}, \mathrm{PM}_{10}$, and $\mathrm{O}_{3}$. Iceland offers a rare setting to study the association of $\mathrm{H}_{2} \mathrm{~S}$ and morbidity and mortality based on the availability of detailed $\mathrm{H}_{2} \mathrm{~S}$ measurements and population-based registries including individual health information. The source of $\mathrm{H}_{2} \mathrm{~S}$ in Reykjavik is two geothermal power plants, Hellisheidarvirkjun and Nesjavallavirkjun, located 26 and $33 \mathrm{~km}$ east of the city, while the other pollutants in this study are mostly trafficrelated. The few existing studies on $\mathrm{H}_{2} \mathrm{~S}$ using mortality and hospital discharge as outcome measures suggest that long-term exposure to moderately high concentrations of $\mathrm{H}_{2} \mathrm{~S}$ is associated with cardiovascular- and respiratory morbidity [33,34]. In Reykjavik, the intermittent concentrations of $\mathrm{H}_{2} \mathrm{~S}$ are not likely to be evenly dispersed over the city, and therefore, these findings call for further analysis of the potential adverse health effects of $\mathrm{H}_{2} \mathrm{~S}$.
An imperative strength of this case-crossover study is the design that adjusts for seasonality, time trends, and slowly time-varying confounders, since the control exposures are within the same season and day of the week as the case exposure. The model makes within-subject comparisons possible and time-independent confounders are controlled for by design. Therefore, individual characteristic adjustments are not needed. In our assessments we controlled for temperature, relative humidity, and influenza season. Further, we tested whether different control samplings affected our results. This was not the case, as the pattern of associations between air pollutants and glyceryl trinitrate dispensing remained similar and statistically significant. Moreover, the Icelandic Medicines Registry is virtually complete, since all filled prescriptions in outpatient settings are registered according to personal identification numbers. Such completeness of a medication registry is quite unique. Finally, glyceryl trinitrates are not prescribed unless the patient has angina pectoris and therefore there is no incidence of dispensing the medication to individuals who do not suffer from cardiovascular disease.

The study has limitations that should be mentioned. Firstly, the data did not allow an identification of whether individuals to whom glyceryl trinitrates was dispensed were previously known to have angina pectoris, or if they were newly diagnosed with angina pectoris at the time of dispensing. Some patients with angina pectoris may of course have had glyceryl trinitrates at hand, ready to use in case of exacerbation, and thus do not need a new dispensation at the time of exacerbation, 
but may fill prescription at later time by way of precaution. Such course of events would diminish the possibility to find an association between drug dispensing and an increase in pollution concentrations with a short lag. Secondly, the air pollution data were only derived from one monitoring station. The study therefore has the inherent weakness that the exposure concentrations were not on an individual basis, but cover the whole population of the Reykjavik area with one station as a proxy for exposure. This monitoring station was the only one available in the Reykjavik area during the study period.

\section{Conclusions}

To our knowledge, this is the first study where the dispensing of glyceryl trinitrates is used as a public health indicator in relation to ambient air pollution. Our results suggest that $\mathrm{NO}_{2}$ and $\mathrm{O}_{3}$ ambient air concentrations may adversely affect cardiovascular health, as measured by the dispensing of the anti-angina pectoris medication, glyceryl trinitrates.

\section{Abbreviations}

$\mathrm{CH}_{4}$ : Methane; $\mathrm{Cl}$ : Confidence interval; $\mathrm{CO}$ : Carbon oxide; $\mathrm{H}_{2} \mathrm{~S}$ : Hydrogen sulfide; $\mathrm{NO}_{2}$ : Nitrogen dioxide; $\mathrm{O}_{3}$ : Ozone; OR: Odds ratio; $\mathrm{PM}_{10}$ : Particulate matter $\leq 10 \mu \mathrm{m}$ in aerodynamic diameter; $\mathrm{PM}_{2.5}$ : Particulate matter $\leq 2.5 \mu \mathrm{m}$ in aerodynamic diameter; SD: Standard deviation; $\mathrm{SO}_{2}$ : Sulfur dioxide.

\section{Competing interest}

The authors have not over the past three years had any financial relations with organizations that might have an interest in the submitted work. The authors hereby declare no relationships or activities that could appear to have influenced the submitted work.

\section{Authors' contributions}

$R G F, H Z, V R$, and $O O$ designed the study. RGF, VR, and $O O$ planned the analysis, OO, RGF, and $\Pi$ analyzed the data, RGF, $H Z$, and $V R$ drafted the article, all authors read the manuscript, interpreted the conclusions, and agreed on the final version.

\section{Acknowledgements}

We thank Kristinn Jonsson, database expert at the Directorate of Health in Iceland, for extracting and merging the data for this study. We also thank Thorsteinn Johannsson, air quality specialist at the Environment Agency of Iceland, for his inspiring support and interest in the study. Two grants were received in supporting this study, one from the Icelandic Centre for Research (Rannis) (R09031/5264); and the other from the Reykjavík Energy Environment and Power Research. The funders did not have any role in the design and conduct of the study; collection, management, analysis, and interpretation of the data; and preparation, review, or approval of the manuscript.

\footnotetext{
Author details

${ }^{1}$ Center of Public Health Sciences, Faculty of Medicine, University of Iceland, Reykjavík, Iceland. 'Environment and Natural Resources, University of Iceland, Reykjavík, Iceland. ${ }^{3}$ Institute of Earth Sciences, University of Iceland, Reykjavík, Iceland. ${ }^{4}$ Department of Preventive Medicine, University of Iceland, Reykjavík, Iceland.
}

Received: 22 February 2013 Accepted: 24 April 2013

Published: 30 April 2013

\section{References}

1. Brook RD, Rajagopalan S, Pope CA III, Brook JR, Bhatnagar A, Diez-Roux AV, Holguin F, Hong Y, Luepker RV, Mittleman MA, Peters A, Siscovick D, Smith SC, Whitsel L Jr, Kaufman JD: Particulate matter air pollution and cardiovascular disease. Circulation 2010, 121:2331-2378.
2. Guo $Y$, Jia $Y$, Pan $X$, Liu L, Wichmann HE: The association between fine particulate air pollution and hospital emergency room visits for cardiovascular diseases in Beijing, China. Sci Total Environ 2009, 407:4826-4830.

3. Pope CA III, Ezzati M, Dockery DW: Fine-particulate air pollution and life expectancy in the United States. N Engl J Med 2009, 360:376-386.

4. Symons JM, Wang L, Guallar E, Howell E, Dominici F, Schwab M, Ange BA, Samet J, Ondov J, Harrison D, Geyh A: A case-crossover study of fine particulate matter air pollution and onset of congestive heart failure symptom exacerbation leading to hospitalization. Am J Epidemiol 2006, 164:421-433.

5. Metzger KB, Tolbert PE, Klein M, Peel JL, Flanders WD, Todd K, Mulholland JA, Ryan PB, Frumkin H: Ambient air pollution and cardiovascular emergency department visits. Epidemiology 2004, 15:46-56.

6. Hoek G, Brunekreef B, Fischer P, van Wijnen J: The association between air pollution and heart failure, arrhythmia, embolism, thrombosis, and other cardiovascular causes of death in a time series study. Epidemiology 2001, 12:355-357

7. Liang W-M, Wei H-Y, Kuo H-W: Association between daily mortality from respiratory and cardiovascular diseases and air pollution in Taiwan. Environ Res 2009, 109:51-58.

8. Levy D, Sheppard L, Checkoway H, Kaufman J, Lumley T, Koenig J, Siscovick D: A case-crossover analysis of particulate matter air pollution and out-of-hospital primary cardiac arrest. Epidemiology 2001, 12:193-199.

9. Puett RC, Hart JE, Suh H, Mittleman M, Laden F: Particulate matter exposures, mortality, and cardiovascular cisease in the Health professionals follow-up study. Environ Health Perspect 2011, 119:1130-1135.

10. Zeghnoun A, Beaudeau P, Carrat F, Delmas V, Boudhabhay O, Gayon F, Guincètre $D$, Czernichow $P$ : Air pollution and respiratory drug sales in the city of Le Havre, France, 1993-1996. Environ Res 1999, 81:224-230.

11. Laurent O, Pedrono G, Filleul L, Segala C, Lefranc A, Schillinger C, Riviée E, Bard D: Influence of socioeconomic deprivation on the relation between air pollution and beta-agonist sales for asthma. Chest 2009, 135:717-723.

12. Pitard A, Zeghnoun A, Courseaux A, Lamberty J, Delmas V, Fossard JL, Villet $H$ : Short-term associations between air pollution and respiratory drug sales. Environ Res 2004, 95:43-52

13. Vegni FE, Castelli B, Auxilia F, Wilkinson P: Air pollution and respiratory drug use in the city of Como, Italy. Eur J Epidemiol 2005, 20:351-358.

14. Carlsen HK, Zoëga H, Valdimarsdóttir U, Gíslason T, Hrafnkelsson B: Hydrogen sulfide and particle matter levels associated with increased dispensing of anti-asthma drugs in Iceland's capital. Environ Res 2012, 113:33-39.

15. Population statistics. http://www.statice.is/Statistics/Population/Urban-nucleiand-zip-codes. Accessed July 62012.

16. Traffic numbers on main roads in Iceland [in Icelandic]. http://www.vegagerdin.is/ vefur2.nsf-/Files/Umferdartolur2005/\$file/Umfer\%C3\%BOart\%C3\%B6lur\%202005. pdf. Accessed July 62012.

17. Furu K, Wettermark B, Andersen M, Martikainen JE, Almarsdottir AB, Sørensen HT: The Nordic countries as a cohort for pharmacoepidemiological research. Basic Clin Pharmacol Toxicol 2010, 106:86-94.

18. WHO collaborating centre for drug statistics methodology. http://www.whocc. no/atc_ddd_index/. Accessed July 62012.

19. Maclure M: The case-crossover design: A method for studying transient effects on the risk of acute events. Am J Epidemiol 1991, 133:144-153.

20. Janes $H$, Sheppard L, Lumley $T$ : Case-crossover analyses of air pollution exposure data: Referent selection strategies and their implications for bias. Epidemiology 2005, 16:717-726.

21. Pope CA III, Verrier RL, Lovett EG, Larson AC, Raizenne ME, Kanner RE, Schwartz J, Villegas GM, Gold DR, Dockery DW: Heart rate variability associated with particulate air pollution. Am Heart J 1999, 138:890-899.

22. Liao D, Creason J, Shy C, Williams R, Watts R, Zweidinger R: Daily variation of particulate air pollution and poor cardiac autonomic control in the elderly. Environ Health Perspect 1999, 107:521-525.

23. Künzli N, Jerrett M, Mack WJ, Beckerman B, LaBree L, Gilliland F, Thomas D, Peters J, Hodis HN: Ambient air pollution and atherosclerosis in Los Angeles. Environ Health Perspect 2005, 113:201-206.

24. Brook RD, Brook JR, Urch B, Vincent R, Rajagopalan S, Silverman F: Inhalation of fine particulate air pollution and ozone causes acute arterial vasoconstriction in healthy adults. Circulation 2002, 105:1534-1536. 
25. Briet $\mathrm{M}$, Collin C, Laurent $\mathrm{S}$, Tan $\mathrm{A}$, Azizi M, Agharazii M, Jeunemaitre $\mathrm{X}$, Alhenc-Gelas F, Boutouyrie P: Endothelial function and chronic exposure to air pollution in normal male subjects. Hypertension 2007, 50:970-976.

26. Hill AB: The environment and disease: Association or causation? Proc Royal Soc Med 1965, 58:295-300.

27. Bhaskaran K, Hajat S, Armstrong B, Haines A, Herrett E, Wilkinson P, Smeeth L: The effects of hourly differences in air pollution on the risk of myocardial infarction: case crossover analysis of the MINAP database. BMJ 2011, 343:d5531.

28. Ruidavets JB, Cournot M, Cassadou S, Giroux M, Meybeck M, Ferrières J: Ozone air pollution is associated with acute myocardial infarction. Circulation 2005, 111:563-569.

29. Peters A, Dockery DW, Muller JE, Mittleman MA: Increased particulate air pollution and the triggering of myocardial infarction. Circulation 2001, 103:2810-2815.

30. von Klot S, Peters A, Aalto P, Bellander T, Berglind N, D'Ippoliti D, Elosua R, Hormann A, Kulmala M, Lanki T, Lowel H, Pekkanen J, Picciotto S, Sunyer J, Forastiere F: Ambient air pollution is associated with increased risk of hospital cardiac readmissions of myocardial infarction survivors in five European cities. Circulation 2005, 112:3073-3079.

31. Poloniecki J, Atkinson R, de Leon A, Anderson H: Daily time series for cardiovascular hospital admissions and previous day's air pollution in London, UK. Occup Environ Med 1997, 54:535-540.

32. Zanobetti A, Schwartz J: The effect of particulate air pollution on emergency admissions for myocardial infarction: a multicity case-crossover analysis. Environ Health Perspect 2005, 113:978-982.

33. Durand M, Wilson JG: Spatial analysis of respiratory disease on an urbanized geothermal field. Environ Res 2006, 101:238-245.

34. Bates MN, Garrett N, Shoemack P: Investigation of health effects of hydrogen sulfide from a geothermal source. Arch Environ Health 2002, 57:405-411.

doi:10.1186/1476-069X-12-38

Cite this article as: Finnbjornsdottir et al: Association of air pollution and use of glyceryl trinitrate against angina pectoris: a population-based case-crossover study. Environmental Health 2013 12:38.

\section{Submit your next manuscript to BioMed Central and take full advantage of:}

- Convenient online submission

- Thorough peer review

- No space constraints or color figure charges

- Immediate publication on acceptance

- Inclusion in PubMed, CAS, Scopus and Google Scholar

- Research which is freely available for redistribution 